\title{
Novel haplotypes and networks of AVR-Pik alleles in Magnaporthe oryzae
}

\author{
Jinbin $\mathrm{Li}^{1^{*}} \mathbb{D}$, Qun Wang ${ }^{1}$, Chengyun $\mathrm{Li}^{2}$, Yunqing $\mathrm{Bi}^{1}$, Xue $\mathrm{Fu}^{1}$ and Raoquan Wang ${ }^{1}$
}

\begin{abstract}
Background: Rice blast disease is one of the most destructive fungal disease of rice worldwide. The avirulence $(A V R)$ genes of Magnaporthe oryzae are recognized by the cognate resistance $(R)$ genes of rice and trigger racespecific resistance. The variation in AVR is one of the major drivers of new races. Detecting the variation in the AVR gene in isolates from a population of Magnaporthe oryzae collected from rice production fields will aid in evaluating the effectiveness of $R$ genes in rice production areas. The Pik gene contains $5 R$ alleles (Pik, Pikh, Pikp, Pikm and Piks) corresponding to the AVR alleles (AVR-Pik $/ \mathrm{kh} / \mathrm{kp} / \mathrm{km} / \mathrm{ks}$ ) of M. oryzae. The Pik gene specifically recognizes and prevents infections by isolates of $M$. oryzae that contain AVR-Pik. The molecular variation in AVR-Pik alleles of M. oryzae and Pik alleles of rice remains unclear.

Results: We studied the possible evolutionary pathways of AVR-Pik alleles by analyzing their DNA sequence variation and assaying their avirulence to the cognate Pik alleles of resistance genes under field conditions in China. The results of PCR products from genomic DNA showed that 278 of the 366 isolates of M. oryzae collected from Yunnan Province, China, carried AVR-Pik alleles. Among the isolates from six regions of Yunnan, 66.7-90.3\% carried AVR-Pik alleles. Moreover, 10 AVR-Pik haplotypes encoding five novel AVR-Pik variants were identified among 201 isolates. The AVR-Pik alleles evolved to virulent from avirulent forms via stepwise base substitution. These findings demonstrate that AVR-Pik alleles are under positive selection and that mutations are responsible for defeating race-specific resistant Pik alleles in nature.

Conclusions: We demonstrated the polymorphism and distribution of AVR-Pik alleles in Yunnan Province, China. By pathogenicity assays used to detect the function of the different haplotypes of AVR-Pik, for the first time, we showed the avoidance and stepwise evolution of AVR-Pik alleles in rice production areas of Yunnan. The functional AVR-Pik possesses diversified sequence structures and is under positive selection in nature.
\end{abstract}

Keywords: Magnaporthe oryzae, Effector, AVR-Pik, Evolution

\section{Background}

In the long history of parasitism, adaptive mutations have occurred between hosts and pathogens, and selection pressure has traditionally been considered the main force driving this coevolution. To date, two hypotheses have been proposed regarding these dynamics: arms race and trench warfare evolution between host resistance genes $(R)$ and pathogen avirulence genes $(A V R)$ [1]. The arms race hypothesis is considered the principal hypothesis, in which both host $R$ genes and pathogen $A V R$ genes are under directional selection and the alleles are derived by mutation. In brief, pathogens evolve a virulence gene to

\footnotetext{
* Correspondence: kmlijinbin@yahoo.com

${ }^{1}$ Agricultural Environment and Resources Research Institute, Yunnan

Academy of Agricultural Sciences, Kunming, China

Full list of author information is available at the end of the article
}

overcome host defense, while the hosts evolve a new resistance allele to defeat the virulence genes of the pathogen. In contrast, in the trench warfare hypothesis, the evolution of both host $R$ genes and pathogen $A V R$ genes is nondirectional.

Rice blast is one of the most destructive diseases in rice-growing regions and is caused by the filamentous ascomycetous fungus Magnaporthe oryzae (synonym of Pyricularia oryzae). Employing resistant rice varieties with major resistance $(R)$ genes is considered the most important strategy for controlling this disease and crop loss that is also environmentally friendly and economical. To date, $\leq 26 R$ genes in rice have been cloned: $P b 1$, Pia, Pib, Pid2, Pid3, Pik, Pikh/Pi54, Pikm, Pikp, Pish, Pit, Pita, Pizt, Pi1, Pi2, Pi5, Pi9, pi21, Pi25, Pi36, Pi37,

(c) The Author(s). 2019 Open Access This article is distributed under the terms of the Creative Commons Attribution 4.0 International License (http://creativecommons.org/licenses/by/4.0/), which permits unrestricted use, distribution, and 
Pi56, Pi63, PiCO39 (http://www.ricedata.cn/gene/gene pi.htm), Pi64 [2] and Pigm [3].

Rice resistance genes can recognize the corresponding $A V R$ of $M$. oryzae and initiate their immune reaction. To date, $12 A V R$ genes in $M$. oryzae have been cloned: AVR-Pi54 [4], AVR-Pi9 [5], AVR-Pib [6], AVR-Pia [7], AVR-Pii [7], AVR-Pik/km/kp [7], AVR-Pizt [8], ACE1 [9], AVR-Pita [10], AVR1-CO39 [11], PWL1 [12], and PWL2 [13]. The $A V R-P i k / \mathrm{km} / \mathrm{kp}$ gene of $M$. oryzae determines the effectiveness of the $R$ gene $P i k / k m / k p$. AVR-Pik/km/kp encodes a putative secreted protein with 113 amino acids and two conserved motifs: motif-1, [LI]xAR[SE][DSE], and motif-2, [RK]CxxCxxxxxxxxxxxxH (similar to the $\mathrm{C} 2 \mathrm{H} 2$ zinc finger motif) [7]. The AVR-Pik/km/kp gene was cloned from an isolate of Ina168 but found to be absent in the assembled sequence of isolate $70-15$, which is recognized by the host Pik resistance protein and triggers the defense response [7]. Five $A V R$-Pik alleles (AVR-Pik-A, $A V R-P i k-B, A V R-P i k-C, A V R-P i k-D$, and $A V R-P i k-E)$ were found [7], and $A V R-P i k-D$ (20.5\%) and AVR-Pik-E (1.4\%) were detected among 77 isolates [14]. Four $A V R$-Pik alleles (AVR-Pik-A, AVR-Pik-C, AVR-Pik-D, and AVR-Pik-E) were found among 39 isolates worldwide (three isolates from Europe, six isolates from America, seven isolates from Africa and 23 isolates from Asia), and $A V R-P i k-D$ was the most frequent allele (15 out 39), while the $A V R-P i k-A$, $A V R-P i k-C$, and $A V R-P i k-E$ alleles had similar frequencies (7-9 out of 39) [15]. AVR-Pik/km/kp has evolved via gene gain/loss [7], while substitution mutations were observed in the coding regions of $A V R-P i k / \mathrm{km} / \mathrm{kp}$ in M. oryzae populations, and 16 single nucleotide polymorphisms (SNPs) were found in regions without signal domains in Chinese rice blast isolates [16].

The Pik locus is located on the long arm of chromosome 11 and is known to have a resistance function [17-20]. At the Pik locus, five rice blast $R$ genes (Pik, Pik-m, Pik-p, Pik-h and Pik-s) are involved, among which $4 R$ genes (Pik, Pik-m, Pik-p and Pik-h) have been isolated $[18,21-24]$ and $P i k$ is regarded as the youngest allele [22]. Pik, Pik-m, Pik-p and Pik-h were cloned and found to encode a putative CC-NBS-LRR protein [18, $23,25,26]$. The CC domain of $P i k-1$ physically binds to the AVR-Pik effector of M. oryzae to trigger Pik-specific resistance $[15,23]$. The rice resistance gene Pik-s is still not cloned. Monogenic lines containing 24 rice blast resistance genes, including $P i k, P i k-m, P i k-p, P i k-h$ and Pik-s, were developed and will be used to characterize the pathogenicity of rice blast fungus [27].

Pikm and Pikp exhibit a high level of resistance to blast fungus from Fujian Province and can be used in parents for resistance breeding in Fujian Province [28]. Pikm, Piks, and Pikp are moderately resistant in Sichuan and Guizhou Provinces, China [29]. Pikm, Piks, and Pik are moderately resistant, while Pikh exhibits high resistance in Guangdong Province, China [30], and $35.4 \%$ of 82 rice germplasm resources were found to carry Pikh by molecular analysis [31]. Eighty of 229 rice cultivars and breeding materials carry the Pik locus in Fujian Province, based on PCR detection [32]. Different resistance spectra of Pik, Pikm, Pikp, Pikh and Piks at the Pik locus were detected in 282 blast isolates collected from Yunnan Province, China [33]. The $R$ genes of the Pik locus exhibit high resistance to Chinese rice blast fungus.

Further understanding the molecular evolution of the $A V R$ gene has potential implications for the development of resistance breeding, the rational use of resistance genes in production, and the deployment of more effective strategies to control the disease. Regarding the long-term interactions between the pathogen and its host, the host employs resistance genes to prevent infection by the pathogen; however, the pathogen attempts to overcome them, and the coevolution of the pathogen and its host becomes discernible at the genome level $[34,35]$. The pathogen utilizes mutation to adapt to novel host alleles and the environment, while its genome structure is highly variable and impacted by host selection $[15,36,37]$. Analyzing DNA sequence variation of AVR-Pik $/ \mathrm{km} / \mathrm{kp}$ alleles of M. oryzae in field isolates will help to understand the effectiveness and durability of the resistance gene Pik alleles in China.

The goal of the present study was to analyze the DNA sequence variation of $A V R-P i k / \mathrm{km} / \mathrm{kp}$ alleles in field isolates of $M$. oryzae to understand the variation and coevolutionary mechanism of M. oryzae AVR-Pik/ $/ \mathrm{km} / \mathrm{kp}$ alleles and rice Pik alleles in Yunnan Province.

\section{Results}

Efficacy of Pik genes and detection frequency of AVR-Pik alleles

Based on the disease reactions, the efficacy of the Pik genes Pik, Pikm, Pikp, Pikh and Piks were examined. Some 223, 256, 154, 276 and 83 of the 366 isolates (collected from different rice growing regions of Yunnan and selected as representative isolates) tested were avirulent to the Pik, Pikm, Pikp, Pikh and Piks gene-containing rice monogenic lines IRBLk-K, IRBLkm-Ts, IRBLkp-K60, IRBLkh-K3 and IRBLks-F5, respectively (Table 1). The frequency of avirulence to Pik, Pikm, Pikp, Pikh and Piks was 60.9, 69.9, 42.1, 75.4 and 22.7\%, respectively, while the remaining 143, 110, 212, 90 and 283 isolates were virulent to the corresponding $R$ gene (Table 1). Of 366 isolates, AVR-Pik/ $\mathrm{km} / \mathrm{kp}$ alleles of 278 were amplified by $A V R-P i k / k m / k p$ (AVR-Pik allele)-specific primers (pex31F/pex31R) (Table 1), and the mean percentage of the $A V R-P i k / \mathrm{km} / \mathrm{kp}$ allele was $76.0 \%$. The highest percentage of $A V R-P i k / k m / k p$ was $90.3 \%$ in the $M$. oryzae population collected from northeastern 
Table 1 Distribution of AVR-Pik genes and avirulent isolates of $M$. oryzae collected from Yunnan, China, in IRBLk-K, IRBLkm-Ts, IRBLkp-K60, and IRBLkh-K3

\begin{tabular}{|c|c|c|c|c|c|c|c|c|}
\hline \multirow[t]{3}{*}{ Locations } & \multirow{3}{*}{$\begin{array}{l}\text { No. of } \\
\text { isolates }\end{array}$} & \multicolumn{2}{|l|}{ PCR detection } & \multicolumn{5}{|c|}{ Pathogenicity assay ${ }^{a}$} \\
\hline & & \multirow{2}{*}{$\begin{array}{l}\text { No. of isolates } \\
\text { with AVR-Pik }\end{array}$} & \multirow{2}{*}{$\begin{array}{l}\text { Frequency } \\
(\%)\end{array}$} & \multicolumn{5}{|c|}{ No. of avirulent isolates and frequency (\%) } \\
\hline & & & & IRBLk-K & IRBLkm-Ts & IRBLkp-K60 & IRBLkh-K3 & IRBLks-F5 \\
\hline Central & 54 & 42 & 77.8 & $40(74.1)$ & $39(72.2)$ & $36(66.7)$ & $43(79.6)$ & $15(27.8)$ \\
\hline Northeastern & 72 & 65 & 90.3 & $62(86.1)$ & $64(88.9)$ & $52(72.2)$ & $68(94.4)$ & $15(20.8)$ \\
\hline Northwestern & 15 & 10 & 66.7 & $2(13.3)$ & $4(26.7)$ & $2(13.3)$ & $5(33.3)$ & $1(6.7)$ \\
\hline Southeastern & 33 & 24 & 72.7 & $24(72.7)$ & $26(78.8)$ & $19(57.6)$ & $27(81.8)$ & $2(6.1)$ \\
\hline Southwestern & 28 & 25 & 89.3 & $16(57.1)$ & $20(71.4)$ & $15(53.6)$ & $22(78.6)$ & $6(21.4)$ \\
\hline Western & 164 & 112 & 68.3 & 79 (48.2) & $103(62.8)$ & $30(18.3)$ & $111(67.7)$ & $44(26.8)$ \\
\hline Total & 366 & 278 & 76.0 & $223(60.9)$ & $256(69.9)$ & $154(42.1)$ & $276(75.4)$ & $83(22.7)$ \\
\hline$X I$ & 149 & 111 & 74.5 & 109 (73.2) & $123(82.6)$ & $73(49.0)$ & $130(87.2)$ & $40(26.8)$ \\
\hline GJ & 217 & 167 & 77.0 & $114(52.5)$ & $133(61.3)$ & 81 (37.3) & $146(67.3)$ & $43(19.8)$ \\
\hline Total & 366 & 278 & 76.0 & $223(60.9)$ & $256(69.9)$ & $154(42.1)$ & $276(75.4)$ & $83(22.7)$ \\
\hline
\end{tabular}

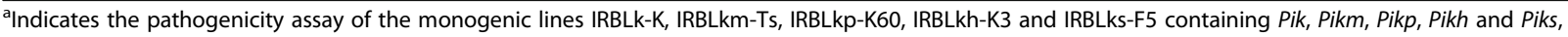
respectively. $X I$ and GJ indicate Xian/Indica and Geng/Japonica, respectively

Yunnan, whereas the lowest percentage was $66.7 \%$ from northwestern Yunnan (Table 1). The percentages of AVR-Pik $/ \mathrm{km} / \mathrm{kp}$ were 77.8, 90.3, 66.7, 72.7, 89.3 and $68.3 \%$ in central, northeastern, northwestern, southeastern, southwestern and western Yunnan, respectively. Similarly, the percentages of $A V R-P i k / k m / k p$ were 74.5 and $77.0 \%$ in Xian/Indica (XI) and Geng/Japonica (GJ) rice-growing regions in Yunnan. These findings suggest that Pik loci have different effective uses in preventing blast infections in most rice production areas in Yunnan.

\section{A novel AVR-Pikh gene was identified to be associated with $A V R-P i k / k m / k p$ alleles}

The $A V R-P i k / k m / k p$ gene is an effector gene with 342 nucleotides encoding a putative secreted protein possessing one signal peptide of 57 nucleotides in the first exon in the open reading frame (ORF) [7]. A total of 10 AVR-Pik haplotypes, including the five original AVR-Pik alleles AVR-Pik_D (GenBank Accession No. AB498875) (H01), AVR-Pik_A (AB498876) (H02), AVR-Pik_B (AB498877) (H03), AVR-Pik_C (AB498878) (H04), and AVR-Pik_E (AB498879) (H05), were identified based on the DNA sequence assemblies of 201 isolates (Table 2). The remaining 77 isolates were sequenced, but they had double peaks and were removed for further analysis. Five novel $A V R-P i k / k m / k p$ haplotypes (H06-H10) were identified. Alignment of DNA sequence assemblies of the $A V R-P i k / \mathrm{km} / \mathrm{kp}$ gene from 201 isolates revealed six polymorphic sites in the exon region, and none of them were in the signal peptide region (Table 2). Six sites in the exon region resulted in amino acid substitutions (Table 3). Moreover, the $A V R-P i k / k m / k p$ allele sequence assemblies among the 201 isolates were predicted to produce 10 functional proteins (Table 3). Among these 10 proteins, amino acid variations were predicted to occur at five positions. All variations occurred throughout the protein, except for the putative secreted proteins possessing the $[\mathrm{RK}]$ CxxCxxxxxxxxxxxxH] motif (Table 3; Additional file 1: Figure S1). Amino acid variations at M78K were found in six isolates, all of which were

Table 2 Haplotypes of AVR-Pik loci in rice blast fungus in Yunnan, China

\begin{tabular}{|c|c|c|c|c|c|c|c|c|}
\hline \multirow[t]{2}{*}{ Haplotype } & \multirow{2}{*}{$\begin{array}{l}\text { No. of } \\
\text { isolates }\end{array}$} & \multirow{2}{*}{$\begin{array}{l}\% \\
\text { of } \\
\text { total }\end{array}$} & \multicolumn{6}{|c|}{ Variant locus $^{\mathrm{a}}$} \\
\hline & & & 136 & 139 & 143 & 200 & 233 & 234 \\
\hline AB498875 (AVR-Pik_D) & & & C & C & G & C & $\mathrm{T}$ & G \\
\hline AB498876 (AVR-Pik_A) & & & A & G & A & . & . & . \\
\hline AB498877(AVR-Pik_B) & & & A & G & A & . & . & A \\
\hline AB498878 (AVR-Pik_C) & & & A & . & . & A & . & . \\
\hline AB498879 (AVR-Pik_E) & & & A & . & . & . & . & . \\
\hline $\mathrm{H} 01$ & 45 & 22.4 & . & . & . & . & . & . \\
\hline $\mathrm{H} 02$ & 46 & 22.9 & A & G & $A$ & . & . & . \\
\hline $\mathrm{H} 03$ & 4 & 2 & A & G & $A$ & . & . & A \\
\hline $\mathrm{HO4}$ & 11 & 5.5 & A & . & . & A & . & . \\
\hline H05 & 51 & 25.4 & A & . & . & . & . & . \\
\hline H06 & 4 & 2 & A & . & A & . & . & . \\
\hline H07 & 27 & 13.4 & . & . & A & . & . & . \\
\hline H08 & 4 & 2 & A & . & A & A & . & . \\
\hline H09 & 3 & 1.5 & . & G & A & . & . & . \\
\hline $\mathrm{H} 10$ & 6 & 3 & A & G & $A$ & . & $A$ & . \\
\hline
\end{tabular}

Indicates the same as AB498875 (GenBank Accession No.). AB498875, AB498876, AB498877, AB498878 and AB498879 of AVR-Pik were obtained from GenBank and represent the five different alleles AVR-Pik_D, AVR-Pik_A, AVR-Pik_B, AVR$P i k \_C$, and AVR-Pik_E, respectively 
Table 3 Variation in the AVR-Pik loci proteins in rice blast fungus in Yunnan, China

\begin{tabular}{|c|c|c|c|c|c|c|c|c|c|c|c|c|}
\hline \multirow[t]{2}{*}{ Haplotype } & \multirow{2}{*}{$\begin{array}{l}\text { Total } \\
\text { isolates }\end{array}$} & \multicolumn{5}{|c|}{ Variant locus ${ }^{\mathrm{a}}$} & \multicolumn{5}{|c|}{ Disease reaction ${ }^{b}$} & \multirow{2}{*}{$\begin{array}{l}\text { Functional } \\
\text { allele }^{c}\end{array}$} \\
\hline & & 46 & 47 & 48 & 67 & 78 & IRBLk-K & IRBLkm-Ts & IRBLkp-K60 & IRBLkh-K3 & IRBLks-F5 & \\
\hline AB498875 & & $\mathrm{H}$ & $P$ & G & A & $M$ & & & & & & AVR-Pik/km/kp ${ }^{\mathrm{d}}$ \\
\hline AB498876 & & $N$ & A & $\mathrm{D}$ & . & . & & & & & & $-d$ \\
\hline AB498877 & & N & A & $\mathrm{D}$ & . & । & & & & & & $-d$ \\
\hline AB498878 & & $N$ & . & . & $D$ & . & & & & & & $-d$ \\
\hline AB498879 & & $N$ & . & . & . & . & & & & & & AVR-Pik $/ \mathrm{km}^{\mathrm{d}}$ \\
\hline $\mathrm{H} 01$ & 45 & . & . & . & . & . & $37 R+8 M$ & $39 R+6 M$ & $26 R+19 M$ & $41 R+4 M$ & $34 S+11 M$ & AVR-Pik/km/kp/kh \\
\hline $\mathrm{H} 02$ & 46 & $N$ & A & $\mathrm{D}$ & . & . & $35 S+11 M$ & $27 S+19 M$ & $38 S+8 M$ & $44 R+2 M$ & $45 S+1 M$ & AVR-Pikh \\
\hline $\mathrm{H} 03$ & 4 & $N$ & A & D & . & I & $4 S$ & $4 \mathrm{~S}$ & $4 S$ & $3 R+1 M$ & $3 S+1 M$ & AVR-Pikh \\
\hline $\mathrm{H} 04$ & 11 & $N$ & . & . & $\mathrm{D}$ & . & $8 S+3 M$ & $5 S+6 M$ & $8 S+3 M$ & $5 S+6 M$ & $8 S+3 M$ & - \\
\hline $\mathrm{H} 05$ & 51 & $N$ & . & . & . & . & $28 R+23 M$ & $49 R+2 M$ & $49 S+2 M$ & $49 R+2 M$ & $26 S+25 M$ & AVR-Pik/km/kh \\
\hline H06 & 4 & $N$ & . & $\mathrm{D}$ & . & . & $3 S+1 M$ & $3 R+1 M$ & $4 S$ & $3 R+1 M$ & $4 S$ & AVR-Pikm/kh \\
\hline $\mathrm{H} 07$ & 27 & . & . & $\mathrm{D}$ & . & . & $25 R+2 M$ & $25 R+2 M$ & $25 R+2 M$ & $24 R+3 M$ & $20 S+7 M$ & AVR-Pik/km/kp/kh \\
\hline $\mathrm{H} 08$ & 4 & $N$ & . & $\mathrm{D}$ & D & . & $4 \mathrm{R}$ & $4 \mathrm{R}$ & $3 S+1 M$ & $4 \mathrm{R}$ & $4 S$ & AVR-Pik/km/kh \\
\hline H09 & 3 & . & A & $\mathrm{D}$ & . & . & $3 R$ & $3 R$ & $2 R+1 M$ & $3 R$ & $1 R+2 S$ & AVR-Pik/km/kp/kh \\
\hline $\mathrm{H} 10$ & 6 & $N$ & A & D & . & K & $6 S$ & $5 S+1 M$ & $5 S+1 M$ & $6 S$ & $6 S$ & - \\
\hline
\end{tabular}

Indicates the same as AB498875

${ }^{b}$ Indicates the pathogenicity assay of the monogenic lines IRBLk-K, IRBLkm-Ts, IRBLkp-K60, IRBLkh-K3, and IRBLks-F5 containing the resistance genes Pik, Pikm, Pikp, Pikh, and Piks, respectively. R, M and S indicate that the disease reaction was resistant, moderately resistant and susceptible, respectively. (Ex.45R indicates that 45 isolates were avirulent to the corresponding monogenic line)

'Indicates a lack of avirulent functional alleles to the corresponding $R$ genes

${ }^{\mathrm{d}}$ The functional alleles from the references of Yoshida et al. [7]: AB498875, AB498876, AB498877, AB498878 and AB498879 are AVR-Pik-D, AVR-Pik-A, AVR-Pik-B, AVR-Pik-C, and AVR-Pik-E, respectively

virulent in the monogenic lines IRBLk-K (with Pik), IRBLkm-Ts (with Pikm), IRBLkp-K60 (with Pikp), IRBLkh-K3 (with $P i k h$ ) and IRBLks-F5 (with Piks) (Table 3). This finding suggests that amino acid $78 \mathrm{M}$ is critical for the avirulence function of $A V R-P i k / \mathrm{km} / \mathrm{kp} /$ $k h$ loci. The isolates of the H01, H07 and H09 haplotypes harbored the avirulence genes $A V R-P i k / \mathrm{km} / \mathrm{kp} / \mathrm{kh}$, the isolates of $\mathrm{H} 05$ and $\mathrm{H} 08$ harbored $A V R-P i k / \mathrm{km} / \mathrm{kh}$, the isolates of $\mathrm{H} 06$ harbored $A V R-P i k m / k h$, and the isolates of $\mathrm{H} 02$ and $\mathrm{H} 03$ harbored AVR-Pikh because these isolates were avirulent to the corresponding $R$ gene(s) (Table 3). The isolates of $\mathrm{H} 04$ and $\mathrm{H} 10$ had overcome the resistance of all Pik alleles at the loci (Table 3). Thus, the novel avirulence gene AVR-Pikh was identified, and the evolution of $A V R$-Pik alleles of $M$. oryzae was involved. The 10 haplotypes did not harbor AVR-Piks because the isolates were virulent to the monogenic line IRBLks-F5 (harboring Pi-ks) (Table 3). Some 75 isolates contained $A V R-P i k / k m / k p / k h$ (frequency of $36.4 \%$ ), 55 isolates contained $A V R-P i k / \mathrm{km} / \mathrm{kh}$ (frequency of $26.7 \%$ ), four isolates contained $A V R-P i k m / k h$ (frequency of $1.9 \%$ ), and 50 isolates contained AVR-Pikh (frequency of 24.9\%). Some 17 isolates did not contain these avirulence genes (Additional file 1: Table S1). In summary, five novel AVR-Pik loci were identified, and $91.5 \%$ of the total isolates contained AVR-Pikh, which is widely distributed in southwestern China.

\section{Stepwise evolution and haplotype diversity of AVR-Pik loci in M. oryzae}

Among the 10 AVR-Pik haplotypes, the haplotypes $\mathrm{H} 01, \mathrm{H} 02, \mathrm{H} 03, \mathrm{H} 04$ and $\mathrm{H} 05$ were identical to the original AVR-Pik alleles of AVR-Pik_D (GenBank Accession No. AB498875), AVR-Pik_A (AB498876), $A V R-P i k_{-} B$ (AB498877), AVR-Pik_C (AB498878), and $A V R-P i k_{-} E$ (AB498879) (Table 2), respectively. Seven haplotypes were detected in 88,37 and $39 M$. oryzae isolates from western, central and northeastern Yunnan, respectively. Six haplotypes were detected in $17 M$. oryzae isolates from southeastern Yunnan, three haplotypes were detected in $10 M$. oryzae isolates from southwestern Yunnan, and only one haplotype was detected in $10 \mathrm{M}$. oryzae isolates from northwestern Yunnan (Table 4). Ten and eight haplotypes were found in the GJ and XI rice-growing regions, and the diversity index (DI) was 0.79 and 0.75 for these regions, respectively. Similarly, the DI was $0.78,0.68$, $0.65,0.62,0.54$, and 0 for northeastern, central, western, southeastern, southwestern, and northwestern Yunnan, respectively (Table 4). In summary, the DI of $A V R-P i k$ alleles was ordered in Yunnan Province as follows: northeastern $>$ central $>$ western $>$ southeastern $>$ southwestern $>$ northwestern. The DI of AVR-Pik alleles in the GJ rice-growing region was similar to that in the $X I$ rice-growing region. 
Table 4 Distribution of AVR-Pik haplotypes in different rice-growing regions

\begin{tabular}{|c|c|c|c|c|c|c|c|c|c|c|}
\hline \multirow[t]{2}{*}{ Haplotype } & \multirow{2}{*}{$\begin{array}{l}\text { No. } \\
\text { isolates }\end{array}$} & \multirow{2}{*}{$\begin{array}{l}\text { Percent } \\
(\%)\end{array}$} & \multicolumn{6}{|l|}{ Regions } & \multicolumn{2}{|c|}{ Production } \\
\hline & & & Northeastern & Central & Southeastern & Western & Northwestern & Southwestern & $X I$ & GJ \\
\hline $\mathrm{H} 01$ & 45 & 21.8 & $12(30.8)^{a}$ & $14(37.8)$ & $10(58.8)$ & $9(10.2)$ & 0 & 0 & $19(30.6)$ & $26(18.7)$ \\
\hline $\mathrm{H} 02$ & 46 & 22.3 & $4(10.3)$ & $2(5.4)$ & $1(5.9)$ & $29(33.0)$ & $10(100)$ & 0 & $2(3.2)$ & $44(31.7)$ \\
\hline $\mathrm{H} 03$ & 4 & 1.9 & $2(5.1)$ & $2(5.4)$ & 0 & 0 & 0 & 0 & 0 & $4(2.9)$ \\
\hline $\mathrm{H} 04$ & 11 & 5.3 & $1(2.6)$ & 0 & $2(11.8)$ & $2(2.3)$ & 0 & $6(60.0)$ & $9(14.5)$ & $2(1.4)$ \\
\hline $\mathrm{H} 05$ & 51 & 24.8 & $9(23.1)$ & 0 & 0 & $42(47.7)$ & 0 & 0 & $22(35.5)$ & $29(20.9)$ \\
\hline H06 & 4 & 1.9 & 0 & $1(2.7)$ & 0 & 0 & 0 & $3(30.0)$ & $3(4.8)$ & $1(0.7)$ \\
\hline $\mathrm{H} 07$ & 27 & 13.1 & $9(23.1)$ & $15(40.5)$ & $1(5.9)$ & $2(2.3)$ & 0 & 0 & $3(4.8)$ & $24(17.3)$ \\
\hline $\mathrm{H} 08$ & 4 & 1.9 & $2(5.1)$ & $1(2.7)$ & $1(5.9)$ & 0 & 0 & 0 & $1(1.6)$ & $3(2.2)$ \\
\hline H09 & 3 & 1.5 & 0 & $2(5.4)$ & 0 & $1(1.1)$ & 0 & 0 & 0 & $3(2.2)$ \\
\hline $\mathrm{H} 10$ & 6 & 2.9 & 0 & 0 & $2(11.8)$ & $3(3.4)$ & 0 & $1(10.0)$ & $3(4.8)$ & $3(2.2)$ \\
\hline Total & 201 & 100 & 39 & 37 & 17 & 88 & 10 & 10 & 62 & 139 \\
\hline \multicolumn{3}{|c|}{ No. of haplotypes } & 7 & 7 & 6 & 7 & 1 & 3 & 8 & 10 \\
\hline \multicolumn{3}{|c|}{ Index of diversity ${ }^{\mathrm{b}}$} & 0.78 & 0.68 & 0.62 & 0.65 & 0.00 & 0.54 & 0.75 & 0.79 \\
\hline
\end{tabular}

${ }^{a}$ Number and frequency (in brackets) of isolates of each haplotype

${ }^{b}$ The diversity index was calculated as the frequency of haplotypes in the $M$. oryzae population following Fontaine's method [38]: diversity index $=\left(1-\sum_{i}^{n}=1 p_{i}{ }^{2}\right)$ (where pi is the frequency of haplotype $\mathrm{i}$ in a population)

Six nucleotide variations in the exons of AVR-Pik alleles were observed (Additional file 1: Figure S1 and Table S2), and a haplotype network based on sequence variation was developed (Fig. 1). Four microevolutionary clusters of AVR-Pik, AVR-Pikm, AVR-Pikp, and AVR-Pikh were observed among 201 field isolates (Fig. 1). The five original AVR-Pik alleles AVR-Pik_D (H01), AVR-Pik_A (H02), AVR-Pik_B (H03), AVR-Pik_C (H04), and AVR-Pik_E (H05) were involved in the networks. The isolates of H01, H05, H07, H08 and H09 were avirulent to IRBLk-K (with Pik), whereas the isolates of H02, H03, H04, H06 and H10 were virulent to Pik (Table 3; Fig. 1). The isolates of H01, $\mathrm{H} 05, \mathrm{H} 06, \mathrm{H} 07, \mathrm{H} 08$ and $\mathrm{H} 09$ were avirulent to IRBLkm-Ts (with Pikm), whereas the isolates of H02, H03, H04, and H10 were virulent to Pikm (Table 3; Fig. 1). The isolates of $\mathrm{H} 01, \mathrm{H} 07$ and $\mathrm{H} 09$ were avirulent to IRBLkp-K60 (with Pikp), whereas the isolates of H02, H03, H04, H05, H06, H08 and H10 were virulent to Pikp (Table 3; Fig. 1). The isolates of H01, H02, H03, H05, H06, H07, H08 and H09 were avirulent to IRBLkh-K3 (with $P i k h)$, whereas the isolates of $\mathrm{H} 04$ and $\mathrm{H} 10$ were virulent to Pikh (Table 3; Fig. 1). These findings suggest that there were four distinct stepwise-evolved patterns (AVR-Pik, $A V R-P i k m, A V R-P i k p$, and AVR-Pikh) in rice-growing regions of Yunnan.

A possible scenario for $M$. oryzae AVR-Pik allele-rice $P i k$ allele interactions and coevolution was constructed (Fig. 2). The AVR-Pik homolog H01 (AVR-Pik-D) was derived from an ancestral $M$. oryzae gene. The Pik allele, Piks, cannot recognize the three alleles AVR-Pik-D (H01), H07 and H09; thus, the other Pik allele, Pikp, evolved that can recognize these three alleles, while the altered alleles $\mathrm{H} 05$ (AVR-Pik-E) and H08 evolved to virulence from avirulence via nucleotide substitution to avoid recognition by Pikp (Table 2; Fig. 2). For this situation, another $P i k$ allele, $P i k$, evolved that can recognize five alleles, namely, AVR-Pik-D (H01), H07, H09, AVR-Pik-E (H05) and H08. Then, yet another AVR-Pik allele, H06, was derived that cannot be recognized by Pikp and Pik. Next, the rice $R$ gene Pikm was utilized that recognizes AVR-Pik-D (H01), H07, H09, $A V R-P i k-E$ (H05), H08 and H06. Then, two more AVRPik alleles, namely, $A V R-P i k-A$ (H02) and AVR-Pik-B (H03), were derived that cannot be recognized by Pikp, $P i k$ and Pikm. Next, the rice $R$ gene Pikh was utilized that recognizes $A V R-P i k-D$ (H01), H07, H09, AVR-Pik-E (H05), H08, H06, AVR-Pik-A (H02) and AVR-Pik-B (H03). Then, another two AVR-Pik alleles, namely, $A V R$ Pik-C (H04) and H10, evolved that cannot be recognized by any of the five Pik alleles (Table 2; Fig. 2). These patterns show the stepwise evolution of $A V R$-Pik and $P i k$ interaction and coevolution. Interestingly, the $A V R-P i k$ allele $\mathrm{H} 07$ was derived from $\mathrm{H} 01$, which can be recognized by Pikp, Pik and Pikm. Thus, the altered allele $\mathrm{H} 06$ from $\mathrm{H} 07$ can avoid recognition by Pikp and Pik; next, the altered allele H08 from H06 can avoid recognition by Pikp, while the altered allele $\mathrm{H} 04$ from $\mathrm{H} 08$ avoids recognition by any of the five $P i k$ alleles. Similarly, the H09 allele was derived from H07, which can be recognized by Pikp, Pik, Pikm and Pikh; thus, the altered allele $\mathrm{H} 02$ allele from $\mathrm{H} 09$ can avoid recognition by Pikp, Pik, and Pikm (Table 2; Fig. 2). The H05 allele can be recognized by $P i k, P i k m$ and Pikh, while the altered allele $\mathrm{H} 04$ from $\mathrm{H} 05$ can avoid recognition by 

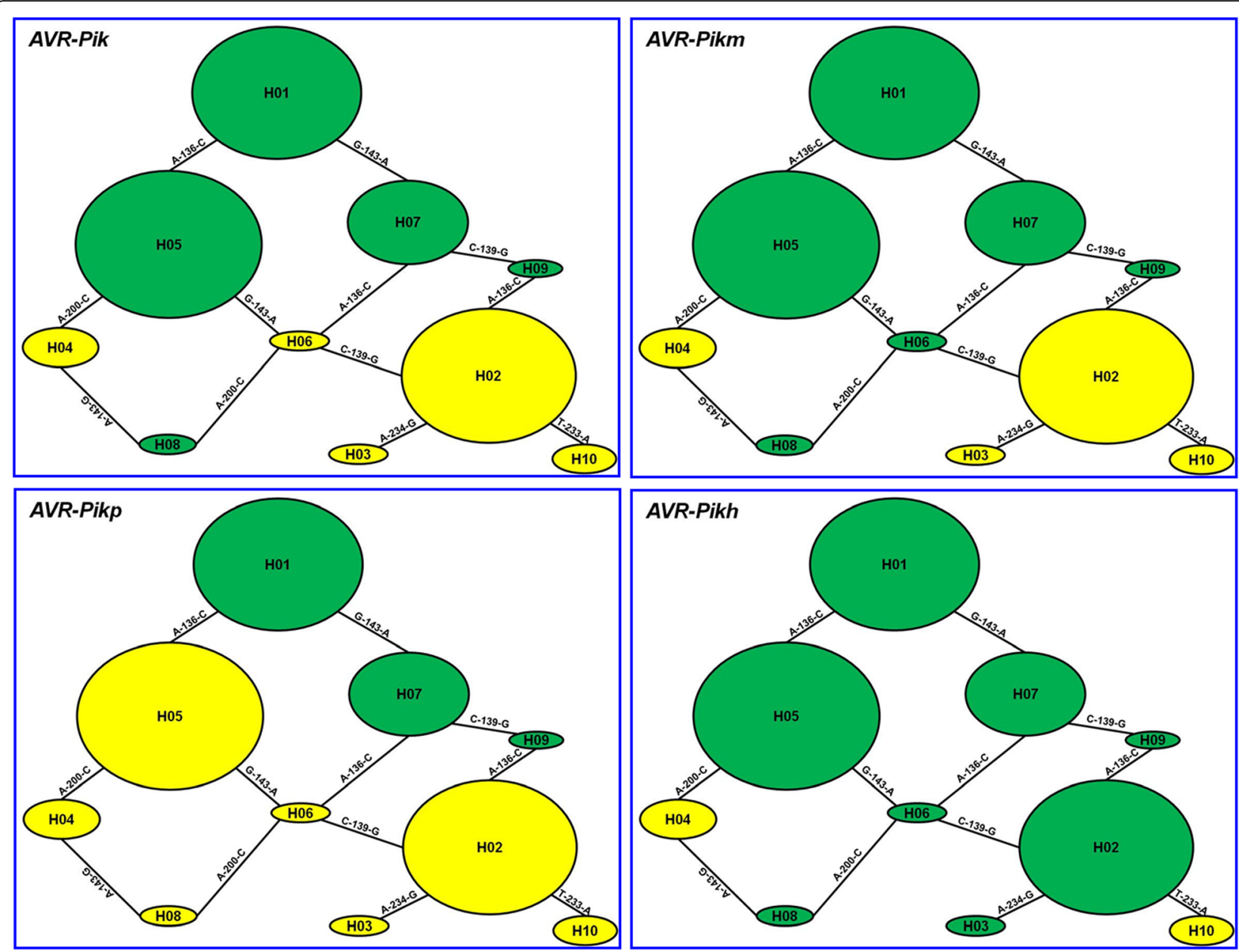

Avirulent to the corresponding $R$ gene

\section{Virulent to the corresponding $R$ gene}

Fig. 1 The haplotype network for the 10 AVR-Pik alleles. The original AVR-Pik allele is designated as the H01 haplotype in the network. Haplotypes are separated by mutational events. All haplotypes are displayed as circles. The size of the circles corresponds to the haplotype frequency. Haplotypes H01 to H05 are the same as AB498875, AB498876, AB498877, AB498878 and AB498879 (GenBank Accession No.) of AVR-Pik and were obtained from GenBank. Green indicates avirulence to the corresponding $R$ gene, and yellow indicates virulence to the corresponding $R$ gene

Pikp, Pik, and Pikm (Table 2; Fig. 2). These results suggest that the avoidance evolution of AVR-Pik loci of $M$. oryzae was involved in the interaction and coevolution with the Pik loci of M. oryzae in nature.

\section{Selection pressure on AVR-Pik in M. oryzae}

To determine the natural selection pressure on $A V R-P i k$ in M. oryzae in Yunnan, Tajima's neutrality of $A V R-P i k$ in M. oryzae was tested based on 201 AVR-Pik DNA sequences, and Tajima's $D$ was found to be 1.19854 (Additional file 1: Table S2). The result suggests that $A V R-P i k$ might be under strong population expansion or either in positive selection. The results of three positive-selection models were highly consistent (Fig. 3). The sliding window shows the distribution of the $\mathrm{Ka} / \mathrm{Ks}$ values across all 113 amino acids under the M8, M8a, and
M7 models (Fig. 3). The results show that the $\mathrm{Ka} / \mathrm{Ks}$ value of the 46th, 47th, 48th, 67th and 78th sites was $>1$, suggesting that these sites were potentially subjected to purifying selection. Positively selected sites were observed only in the mature protein region among the $201 \mathrm{M}$. oryzae isolates with $A V R$-Pik (Fig. 3). These results showed that the amino acid sequence was conserved in the signal peptide compared with the divergent mature protein region of $A V R$-Pik in M. oryzae.

To confirm the resistance of Pik alleles in the field, we assayed seedling and panicle blast disease with monogenic lines carrying Pik, Pikm, Pikp, and Pikh, which were developed by the Japan International Research Center for Agricultural Sciences (JIRCAS) and International Rice Research Institute (IRRI) in fields in Mangshi, Lufeng and Yiliang Counties in 2015 (Additional file 1: Table S3). The result suggests that IRBLkm-Ts (with Pikm), IRBLkp-K60 


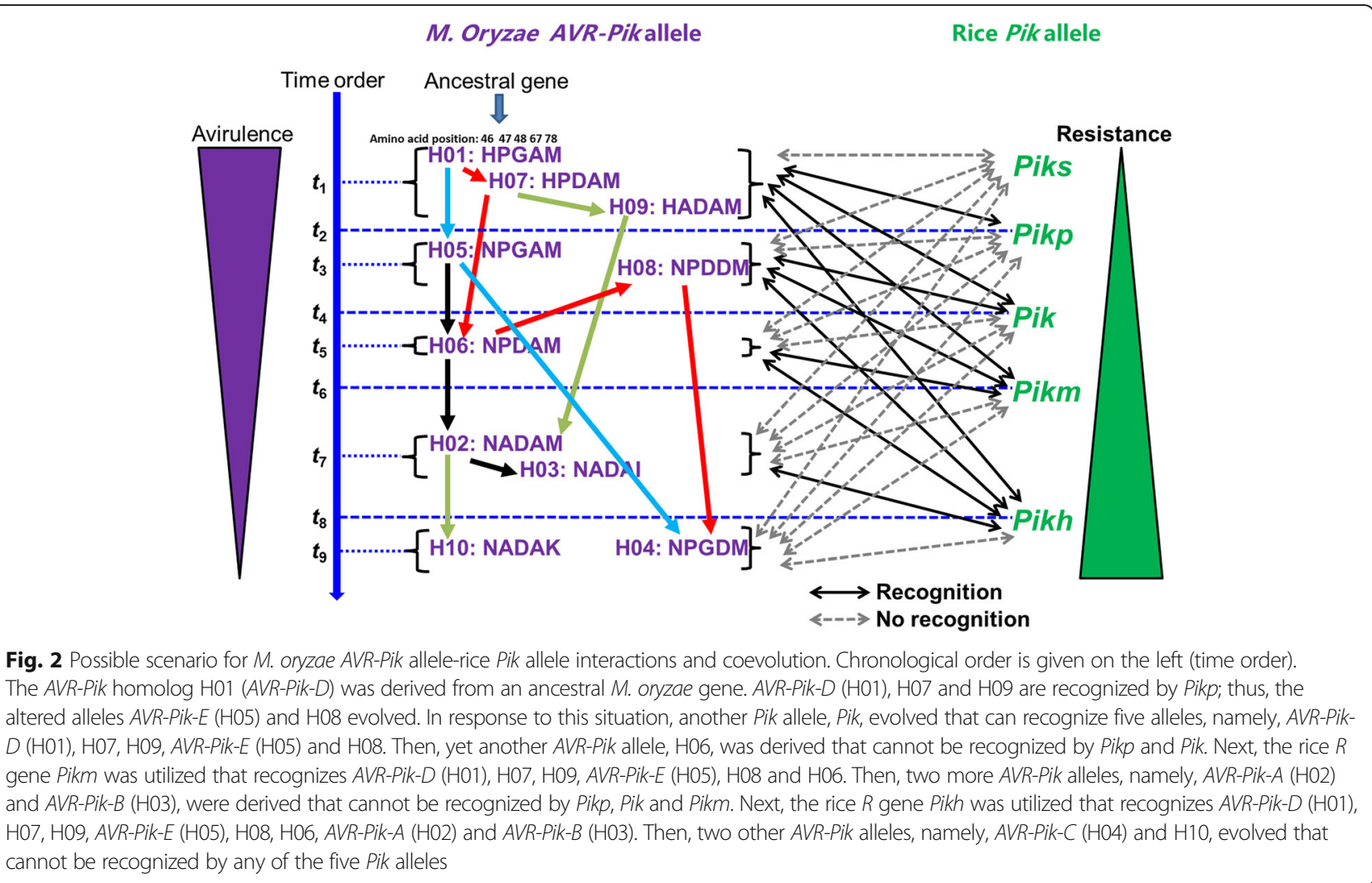

(with Pikp), and IRBLkh-K3 (with Pikh) were resistant, while IRBLks-F5 (with Piks) and IRBLk-Ka (with Pik) were susceptible in Mangshi County (Additional file 1: Table S3). These results suggest that $M$. oryzae isolates in the population holds $A V R-P i k m / k p / k h$ genes. IRBLkh-K3 (with Pikh) was resistant in Lufeng and Yiliang, and the monogenic lines IRBLks-F5 (with Piks), IRBLk-Ka (with Pik), IRBLkm-Ts (with Pikm) and IRBLkp-K60 (with Pikp) were susceptible in Lufeng and Yiliang Counties, suggesting that the $M$. oryzae isolates in the population harbor

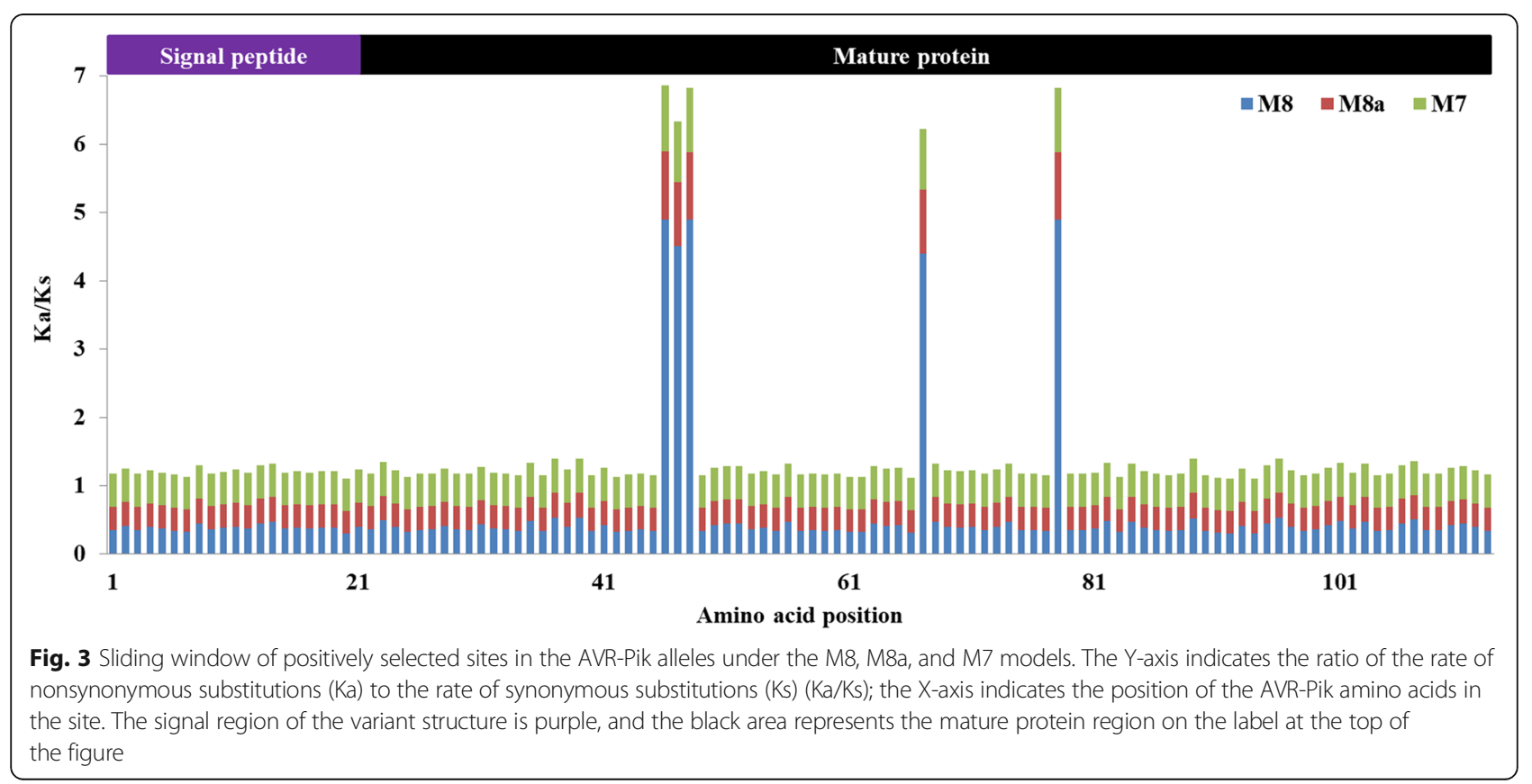


AVR-Pikh. These results are consistent with the results of PCR detection and pathogenicity assays.

\section{Discussion}

In this study, we found five new haplotypes in the $A V R$ $P i k$ DNA sequences among field isolates of $M$. oryzae from various rice-producing regions in Yunnan. Numerous virulent isolates of the $P i k$ gene containing rice varieties were identified in field isolates collected in Yunnan, suggesting that $P i k$ was eradicated in some rice production areas due to the extensive development of $P i k$ in China. The Pik alleles have been deployed and display high rice blast resistance in China $[20,22,32$, 39]. Complete deletions have occurred in AVR-Pik sequences among field isolates of $M$. oryzae from various rice-producing countries $[15,16]$, which agrees with our results. Numerous isolates inspected from commercial rice fields containing $A V R$-Pik suggest that $P i k$ has been effective in preventing rice blast disease. In Yunnan, rice cultivars with Pikh, Pikp, Pikm, Piks, and Pik were resistant to $81.7,62.8,51.9,43.4$ and $39.4 \%$ of isolates (282 isolates), respectively [33]. The corresponding values of 146 isolates from Guangdong Province were 88.4, 39.0, $0,1.4$ and $57.5 \%$, respectively [40]. These results suggest that some Pik alleles have limited effects in these rice production areas. Continued analysis of $A V R$-Pik alleles in these isolates will help us understand the evolutionary mechanism of $A V R$-Pik and predict the stability and effectiveness of $P i k$ allele-mediated resistance under natural conditions.

Effective variations in DNA sequences have been observed in the telomere regions of several $A V R$ genes (AVR-Pita1, AVR-Pia, and AVR-Pii) [7, 41, 42]. The transposable element (TE) insertion in the last exon of the ACE1 gene [9] and Pot3 inserted in AVR-Pizt and AVR-Pita1 all resulted in new virulent alleles. Based on the DNA sequence analysis $[8,43,44]$, four variations, namely, a point mutation, segmental deletion, complete absence (6.7\%) and TE insertion, were found in AVR-Pib, all of which result in loss of the avirulence function [6]. Three distinct expression profiles were found among seven of 16 functional nucleotide polymorphisms in the $A V R-P i b$ genes [6]. These findings showed that $M$. oryzae uses transposons to change the expression of $A V R$ genes to overcome $R$ genes. In the present study, the $A V R-P i k$ gene was present in most blast populations (76.0\%) in Yunnan (Table 1), which was similar to rice blast isolates in Hunan Province [45]. We found significantly more nucleotide variation in the protein-coding region of $A V R$-Pik alleles, resulting in changes in amino acids and suggesting that there is intense selection pressure on $A V R$-Pik alleles in Yunnan.

DNA sequence variation was found in exon regions of $A V R-P i k$, and a total of 10 haplotypes were identified based on the six variant nucleotides among 201 isolates collected from Yunnan (Table 2). Five novel variant amino acids of the AVR-Pik loci variants in the 201 isolates were identified in the present study, which leads towards finding of five new haplotypes. Based on the virulence analysis of the strains harboring this variation, haplotypes $\mathrm{H} 01, \mathrm{H} 02, \mathrm{H} 05$ and $\mathrm{H} 07$ are more frequent in the field isolates. This result suggests that the loss of these haplotypes may have a larger fitness penalty than the loss of other alleles in the $M$. oryzae population. These new alleles allowed us to construct a more holonomic network among different alleles of AVR-Pik, and some novel haplotypes were found. We also identified the putative secreted proteins possessing the [LI]xAR[ SE][DSE] and [RK]CxxCxxxxxxxxxxxxH] motifs in 201 isolates with $A V R-P i k$ alleles (Table 3), which was consistent with the results of Yoshida et al. [7]. Some $126,59,94$ and 15 isolates are variations at the amino acid positions $\mathrm{H} 46 \mathrm{~N}, \mathrm{P} 47 \mathrm{~A}, \mathrm{G} 48 \mathrm{D}$, and A67D, respectively, and four and six isolates are variations at the amino acid positions $\mathrm{M} 78 \mathrm{I}$ and $\mathrm{M} 78 \mathrm{~K}$, respectively (Table 3). These results showed that the 46th, 47th, 48th, 67th and 78th amino acid positions were the most variable amino acid sites among proteins of AVR-Pik/ $\mathrm{km} / \mathrm{kp} / \mathrm{kh}$.

During the long coevolution of plants and pathogens, the pathogen $A V R$ genes have been recognized by the cognate plant $R$ genes and triggered effective defense responses. The divergences of the AVR genes of the pathogen were shaped by host $R$ genes and changing environmental conditions. We observed that the DI of AVR-Pik was similar in the XI and GJ regions (Table 4), and variations in $A V R$-Pik were different between the XIand GJ-growing regions (Table 4). These results suggest that adaptive variations have occurred in commercial rice fields in Yunnan.

Yunnan is one of the diversification centers of the cultivated Asian rice species Oryza sativa. The three wild species $O$. rufipogon, O. officinalis and $O$. meyeriana also exist in the area [46]. Over 5000 accessions of rice germplasms were collected from fields and preserved. Among them, 227 rice accessions were characterized by a set of differential rice blast isolates, and 38 and 25 of 227 rice accessions contained the rice blast resistance genes Pik and Pikm, respectively [46]. The observed Tajima's $D$ of 1.19854 (Additional file 1: Table S2) suggests that $A V R-P i k / \mathrm{km} / \mathrm{kp} / \mathrm{kh}$ loci may be under population expansion or purifying selection shaped by the cognate Pik loci in rice-growing regions of Yunnan. Most isolates carried AVR-Pikh and Pikh, with high resistance, in Yunnan and Guangdong Provinces. This pattern may be due to Pikh being a widely distributed resistance gene in rice accessions. These results agree with those of Zhai et al. [22]. 
$A V R-P i k$ is recognized specifically by the $P i k$ in rice, and AVR-Pik directly physically binds the $\mathrm{N}$-terminal coiled-coil domain of Pik. These observations were confirmed by yeast two-hybrid and coimmunoprecipitation assays [15]. Four alleles of $A V R-P i k$ ( $A V R-P i k \_D$, $A V R-P i k_{-} E, A V R-P i k_{-} A$, and AVR-Pik_C) in Japanese isolate populations coevolved with the rice $P i k$ alleles Pikp, Pik and Pikm [15]. Four alleles of AVR-Pik in the Chinese $M$. oryzae population showed stepwise evolution with the rice Pik alleles Pikp, Pik, Pikm, and Pkh [16]. Highly variable $P i k$ alleles were observed, and stepwise changes in both the AVR-Pik of M. oryzae and Pik of rice were found in the field [16]. These observations indicate that AVR-Pik has been strongly targeted by hosts [16]. In the present study, we found both avoidance and stepwise-evolved $A V R$-Pik allele-rice Pik allele interactions and coevolution (Table 3; Fig. 2), which implies the presence of a high diversity of rice varieties in Yunnan. The AVR-Pik alleles have been regularly under selection by antagonistic alleles in host populations. Similarly, the wheat-infecting lineages from Brazil and Bangladesh appeared to be genetically distinct and displayed reticulate evolution in population genomic analyses of transcriptomic SNPs [47].

A stepwise mutation process has been demonstrated for virulence acquisition in Fusarium oxysporum f. sp. ciceris and Puccinia striiformis f. sp. tritici [48-50]. In the present study, we found one major episode of mutation evolution of $A V R$-Pik alleles and seven minor mutation evolution patterns (Fig. 2). The alternative mutation pattern can seemingly convert from avirulence to virulence via occasional mutation and showed higher efficiency (Fig. 2). These results may be due to the strong positive selection pressure imposed by the corresponding Pik allele of the host and the environment. Similarly, AVRL567 can convert from avirulent to virulent by a set of stepwise mutations leading to amino acid substitution [51]. Stepwise evolution has been observed in AVR-Pik [15, 16]. The possible evolution of $A V R-P i k$ found in the present study was more complex than expected in the rice-growing regions of Yunnan.

\section{Conclusion}

We detected five novel haplotypes in the field population by using 201 isolates, constructed a complex network of $A V R$-Pik alleles, and evaluated the effectiveness of Pik alleles in rice production areas of Yunnan. Our findings support the premise that functional AVR-Pik possesses diversified sequence structures and can avoid recognition by hosts via multiple site variations. Haplotype $\mathrm{H} 10$ originates from the frequently distributed $\mathrm{H} 2$ haplotype, and $\mathrm{H} 4$ originated from $\mathrm{H} 5$ and/or H8. These haplotypes can overcome all detected Pik alleles to date. Although the $\mathrm{H} 4$ and $\mathrm{H} 10$ haplotypes have low frequencies, surveillance of these two alleles in field populations is crucial because of their high risk of increasing in abundance in the background of Pik-containing rice varieties. Management must retard selection on the allele, possibly by avoiding its proliferation in agricultural practices. The prediction of blast occurrence should be based on the frequency and distribution of the allele of multiple loci, e.g., Pik and AVR-Pik, in isolate populations under field conditions.

\section{Methods}

Rice cultivars, fungal isolates, culture, and pathogenicity assays

The Pik, Pikm, Pikp, Pikh, and Piks gene-containing rice monogenic lines IRBLk-K, IRBLkm-Ts, IRBLkp-K60, IRBLkh-K3 and IRBLks-F5, respectively, and the susceptible backcrossing parent Lijiangxintuanheigu (LTH, without $P i k$ ) were used for pathogenicity assays (the seeds were originally acquired from Japan International Research Center for Agricultural Sciences (JIRCAS), and the JIRCAS undertook the formal identification of the plant material. The seeds conserved in plant germplasm resources bank of Yunnan Academy of Agricultural Sciences). A total of 366 isolates were collected, single-spore purified, and examined. All isolates were stored at $-20^{\circ} \mathrm{C}$ on filter paper and grown in petri dishes containing oatmeal agar for spore production at room temperature under blue and white fluorescent lighting. Disease reactions were determined using a modified standard pathogenicity assay, as described by Jia et al. [52] Specifically, rice seedlings at the 3- to 4-leaf stage were placed in a plastic bag and spray inoculated with a spore suspension of $1-5 \times 10^{5}$ spores $/ \mathrm{mL}$. After inoculation, the plastic bags were sealed to maintain a high relative humidity $(90-100 \%)$ for $24 \mathrm{~h}$ before removing the plants from the bags. Subsequently, the plants were maintained in a greenhouse for an additional 6 days to allow the development of disease symptoms. The disease reactions were rated visually based on the number and extent of lesions on the second youngest leaf using the $0-5$ disease scale. A value of $0-1$ indicated resistant, 2 indicated moderately resistant, and 3-5 indicated susceptible. Five seedlings were used each time, the experiment was repeated once more, and the mean disease scores were used to determine resistance versus susceptibility.

DNA preparation, PCR amplification, and DNA sequencing Fungal isolates were grown in complete liquid media at $25^{\circ} \mathrm{C}$ for six to 8 days to produce mycelia under dark conditions. DNA was then isolated from mycelia using the cetyl trimethylammonium bromide (CTAB) method [53]. The primers pex31F $\left(5^{\prime}\right.$-TCGCCTTCCCATTTTTA-3') and pex31R (5'-GCCCATGCATTATCTTAT-3') were used to amplify the AVR-Pik allele and for sequencing 
using the methods of Yoshida et al. [7]. Specifically, PCRs were performed using $2 \times$ Taq PCR MasterMix (Tiangen Biotech Co. Ltd., Beijing, China). Each PCR consisted of the following components: $25 \mu \mathrm{l}$ of Taq PCR Master Mix (containing $25 \mathrm{U}$ of Taq DNA polymerase, 10X Tiangen PCR buffer, $15 \mathrm{mM} \mathrm{MgCl} 2$, and $200 \mu \mathrm{M}$ each dNTP), $1 \mu \mathrm{l}$ of each $10 \mu \mathrm{M}$ primer, $2 \mu \mathrm{l}$ of fungal genomic DNA, and $21 \mu \mathrm{l}$ of distilled water (provided in the Tiangen kit). Reactions were performed in a Bio-Rad Thermal Cycler (C1000, Bio-Rad Laboratories, Life Science Research, CA, USA) with the following PCR program: 1 cycle at $95^{\circ} \mathrm{C}$ for 3 min for initial denaturation, followed by 29 cycles at $95^{\circ}$ $\mathrm{C}$ for $30 \mathrm{~s}, 60^{\circ} \mathrm{C}$ for $30 \mathrm{~s}$, and $72^{\circ} \mathrm{C}$ for $30 \mathrm{~s}$ and a final denaturation at $72^{\circ} \mathrm{C}$ for $7 \mathrm{~min}$. All PCRs were repeated three times ( $20 \mu \mathrm{l}$ for detection, $50 \mu \mathrm{l}$ for sequencing). The size of the amplified fragment was estimated by DL2000 DNA Ladder (Tiangen Biotech Co. Ltd., Beijing, China). PCR products were sequenced using the same primers as mentioned above for PCR amplification. DNA was sequenced by Shanghai Life Technologies Biotechnology Co., Ltd. (Shanghai, China). The amplicon from each isolate was sequenced three times.

\section{Resistance evaluation of Pik alleles in the field}

The monogenic lines IRBLk-Ka, IRBLkm-Ts, IRBLks-F5, IRBLkp-K60, and IRBLkh-K3 (carrying Pik, Pikm, Piks, Pikp, and Pikh, respectively) were planted in fields in Mangshi, Lufeng and Yiliang Counties in Yunnan Province in 2015. The seedlings and panicles were surveyed for blast disease, and the resistance was evaluated.

\section{Data analysis}

DNA sequences of $A V R$-Pik were assembled by the Vector NTI V.10 software suite (Invitrogen, Carlsbad, California, USA) and aligned using DNASTAR V7.10 software (http://www.dnastar.com/). The number of DNA haplotypes and polymorphic sites $(\pi)$ and the sliding window were calculated using DnaSP v5.10.01 software [54]. Haplotype network analysis was performed using TCS1.21 (http://darwin.uvigo.es/) [55]. The DI was calculated as the frequency of haplotypes or protein types in the rice blast fungus population following the method of Fontaine et al. [38]: $\mathrm{DI}=\left(1-\sum_{\mathrm{i}=1}^{\mathrm{n}} \mathrm{p}_{\mathrm{i}}^{2}\right)$, where $\mathrm{pi}$ is the frequency of haplotype $\mathrm{i}$ in a population. Tajima's neutrality test was performed using MEGA V5.10. The analysis of positive selection was performed using the Selection Server program (http://selecton.tau.ac.il). Three models were used to identify the positively selected sites under the query of AVR-Pik: M8 (positive selection enabled, beta $+\mathrm{w} \geq 1$ ), M8a (beta $+\mathrm{w}=1$, null model), and M7 (beta, null model). The data were then imported into Microsoft Excel for statistical analysis and to draw the sliding window.

\section{Additional file}

Additional file 1: Figure S1. Diversification of AVR-Pik in avirulent isolates. The distribution of variation in the AVR-Pik alleles was analyzed using a sliding window. The $X$-axis shows the distribution of variation within the entire region, including the signal peptide and exon of AVRPik. The lower pane indicates the corresponding schematic representation of the signal peptide and exon of AVR-Pik. Window length: 1; step size: 1. The $\pi$ value corresponds to the level of variation at each site because it is the sum of pairwise differences divided by the number of pairs within the population. Table S1. Distribution of AVR-Pik loci in rice blast fungus. Table S2. Tajima's neutrality test of AVR-Pik in M. oryzae. The analysis involved 201 nucleotide sequences of AVR-Pik. $m$ indicates the number of sequences, $S$ indicates the number of segregating sites, Ps indicates $S / n$, $\Theta$ indicates $p_{s} / a_{1}, \pi$ indicates nucleotide diversity, and $D$ is the Tajima test statistic. Tajima's D: 1.19854, statistical significance: not significant, $P>$ 0.10. Table S3. Summary of the disease reaction of monogenic lines with Pik alleles in fields. Pathogenicity assay of the monogenic lines IRBLk-K, IRBLkm-Ts, IRBLkp-K60, IRBLkh-K3, and IRBLks-F5 containing the resistance genes Pik, Pikm, Pikp, Pikh, and Piks, respectively. $\mathrm{R}$ and S indicate that the disease reaction was resistant and susceptible, respectively. (DOC $142 \mathrm{~kb}$ )

\section{Abbreviations}

AVR: Avirulence gene; CTAB: Cetyl trimethylammonium bromide; DI: Diversity index; GJ: Geng/Japonica; Ka: The rate of nonsynonymous substitution; Ks: The rate of synonymous substitution; LTH: Lijiangxintuanheigu; ORF: Open reading frame; R: Resistance; TE: Transposable element; XI: Xian/Indica

\section{Acknowledgments}

The authors thank Professor Michael A Fullen (The University of Wolverhampton) for useful discussions and for proofreading this manuscript.

\section{Funding}

This work was supported by the National Natural Science Foundation of China (31460454) and the Department of Sciences and Technology of Yunnan Province, China (2015HB076 and 2017FA013), to Jinbin Li and the National Key R\&D Program of China (2017YFD0200400). The funders had no role in study design, data collection, data analysis, data interpretation, the writing of the manuscript or decision to publish.

\section{Availability of data and materials}

The nucleotide sequences of novel AVR-Pik alleles from these isolates have been deposited in GenBank (accession numbers: MK327186 to MK327190; J. Li et al., unpublished).

\section{Authors' contributions}

$J \mathrm{~L}$ conceived the idea and performed the experiment and analysis; QW, YB, XF and RW performed the experiment and analysis; $J L$ and QW drafted the manuscript; and $C L$ revised the manuscript. All authors read and approved the final manuscript.

Ethics approval and consent to participate Not applicable.

Consent for publication

Not applicable.

\section{Competing interests}

The authors declare that they have no competing interests.

\section{Publisher's Note}

Springer Nature remains neutral with regard to jurisdictional claims in published maps and institutional affiliations.

\section{Author details}

${ }^{1}$ Agricultural Environment and Resources Research Institute, Yunnan Academy of Agricultural Sciences, Kunming, China. ${ }^{2}$ The Ministry of Education Key Laboratory for Agricultural Biodiversity and Pest Management, Yunnan Agricultural University, Kunming, China. 
Received: 20 March 2019 Accepted: 2 May 2019

\section{Published online: 16 May 2019}

\section{References}

1. Woolhouse M, Webster J, Domingo E, Charlesworth B, Levin B. Biological and biomedical implications of the co-evolution of pathogens and their hosts. Nat Genet. 2002;32(4):569-77.

2. Ma J, Lei C, Xu X, Hao K, Wang J, Cheng Z, et al. Pi64, encoding a novel CCNBS-LRR protein, confers resistance to leaf and neck blast in rice. Mol PlantMicrobe Interact. 2015;28(5):558-68

3. Deng Y, Zhai K, Xie Z, Yang D, Zhu X, Liu J, et al. Epigenetic regulation of antagonistic receptors confers rice blast resistance with yield balance. Science. 2017;355(6328):962-5.

4. Ray S, Singh PK, Gupta DK, Mahato AK, Sarkar C, Rathour R, et al. Analysis of Magnaporthe oryzae genome reveals a fungal effector, which is able to induce resistance response in transgenic rice line containing resistance gene, Pi54. Front Plant Sci. 2016;7:1-16. https://doi. org/10.3389/fpls.2016.01140

5. Wu J, Kou Y, Bao J, Li Y, Tang M, Zhu X, et al. Comparative genomics identifies the Magnaporthe oryzae avirulence effector AvrPi9 that triggers Pi9-mediated blast resistance in rice. New Phytol. 2015;206:1463-75.

6. Zhang S, Wang L, Wu W, He L, Yang X, Pan Q. Function and evolution of Magnaporthe oryzae avirulence gene AvrPib responding to the rice blast resistance gene Pib. Sci Rep. 2015;5:11642. https://doi.org/10.1038/ srep11642.

7. Yoshida K, Saitoh H, Fujisawa S, Kanzaki H, Matsumura H, Yoshida K, et al. Association genetics reveals three novel avirulence genes from the rice blast fungal pathogen Magnaporthe oryzae. Plant Cell. 2009;21(5):1573-91.

8. Li W, Wang B, Wu J, Lu G, Hu Y, Zhang X, et al. The Magnaporthe oryzae avirulence gene AVR-Pizt encodes a predicted secreted protein that triggers the immunity in rice mediated by the blast resistance gene Piz-t. Mol PlantMicrobe Interact. 2009;22(4):411-20

9. Fudal I, Bohnert HU, Tharreau D, Lebrun MH. Transposition of MINE, a composite retrotransposon, in the avirulence gene ACE1 of the rice blast fungus Magnaporthe grisea. Fungal Genet Biol. 2005;42(9):761-72.

10. Orbach MJ, Farrall L, Sweigard JA, Chumley FG, Valent B. A telomeric avirulence gene determines efficacy for the rice blast resistance gene Pi-ta. Plant Cell. 2000;12(11):2019-32.

11. Farman ML, Leong SA. Chromosome walking to the AVR1-CO39 avirulence gene of Magnaporthe grisea: discrepancy between the physical and genetic maps. Genetics. 1998;150:1049-58.

12. Kang S, Sweigard JA, Valent B. The PWL host specificity gene family in the blast fungus Magnaporthe grisea. Mol Plant-Microbe Interact. 1995; 8(6):939-48.

13. Sweigard JA. Identification, cloning, and characterization of PWL2, a gene for host species specificity in the rice blast fungus. Plant Cell. 1995;7:1221-33.

14. Selisana SM, Yanoria MJ, Quime B, Chaipanya C, Lu G, Opulencia R, et al. Avirulence (AVR) gene-based diagnosis complements existing pathogen surveillance tools for effective deployment of resistance $(R)$ genes against rice blast disease. Phytopathology. 2017;107(6):711-20.

15. Kanzaki H, Yoshida K, Saitoh H, Fujisaki K, Hirabuchi A, Alaux L, et al. Arms race co-evolution of Magnaporthe oryzae AVR-Pik and rice Pik genes driven by their phyical interactions. Plant J. 2012;72(6):894-907.

16. Wu W, Wang L, Zhang S, Li Z, Zhang Y, Lin F, et al. Stepwise arms race between AvrPik and Pik alleles in the rice blast pathosystem. Mol PlantMicrobe Interact. 2014;27(8):759-69.

17. Kiyosawa S. With genetic view on the mechanism of resistance and virulence. Jpn J Genet. 1987:41:89-92 In Japanese.

18. Ashikawa I, Hayashi N, Yamane H, Kanamori H, Wu J, et al. Two adjacent nucleotide-binding site-leucine-rich repeat class genes are required to confer Pikm-specific rice blast resistance. Genetics. 2008;180(4):2267-76.

19. Xu X, Hayashi N, Wang C, Kato H, Fujimura T, Kawasaki S. Efficient authentic fine mapping of the rice blast resistance gene Pik-h in the Pik cluster, using new Pik-h-differentiating isolates. Mol Breed. 2008;22(2):289-99.

20. Wang $L, X u X$, Lin F, Pan Q. Characterization of rice blast resistance genes in the Pik cluster and fine mapping of the Pik-p locus. Phytopathology. 2009; 99(8):900-5.

21. Ashikawa I, Hayashi N, Abe F, Wu J, Matsumoto T. Characterization of the rice blast resistance gene Pik cloned from Kanto51. Mol Breed. 2012;30(1):485-94.
22. Zhai C, Lin F, Dong Z, He X, Yuan B, Zeng X, et al. The isolation and characterization of Pik, a rice blast resistance gene which emerged after rice domestication. New Phytol. 2011;189(1):321-34.

23. Zhai C, Zhang Y, Yao N, Lin F, Liu Z, Dong Z, et al. Function and interaction of the coupled genes responsible for Pik-h encoded rice blast resistance. PLoS One. 2014;9(6):e98067. https://doi.org/10.1371/journal.pone.0098067.

24. Sharma TR, Madhav MS, Singh BK, Shanker P, Jana TK, Dalal V, et al. Highresolution mapping, cloning and molecular characterization of the Pi- $K^{h}$ gene of rice, which confers resistance to Magnaporthe grisea. Mol Gen Genomics. 2005;274(6):569-78.

25. Chen J, Peng P, Tian J, He Y, Zhang L, Liu Z, et al. Pik, a rice blast resistance allele consisting of two adjacent NBS-LRR genes, was identified as a novel allele at the Pik locus. Mol Breed. 2015;35:117. https://doi.org/10.1007/ s11032-015-0305-6.

26. Yuan B, Zhai C, Wang W, Zeng X, Xu X, Hu H, et al. The Pik-p resistance to Magnaporthe oryzae in rice is mediated by a pair of closely linked CC-NBSLRR genes. Theor Appl Genet. 2011;122(5):1017-28. https://doi.org/10.1007/ s00122-010-1506.

27. Tsunematsu H, Yanoria MJT, Ebron LA, Hayashi N, Ando I, Kato H, et al. Development of monogenic lines of rice for blast resistance. Breed Sci. 2000;50(3):229-34

28. Du Y, Ruan H, Shi N, Gan L, Yang X, Chen F. Pathogenicity analysis of Magnaporthe grisea against major Pi-genes and main rice varieties in Fujian Province. J Plant Prot. 2016;43(3):442-51 In Chinese.

29. Zhang S, Zhong X, Qiao G, Shen L, Zhou T, Peng Y. Difference in virulence of Magnaporthe oryzae from Sichuan, Chongqing and Guizhou. Southwest China J Agric Sci. 2017;30(2):359-65 In Chinese.

30. Yang J, Chen S, Zeng L, Li Y, Chen Z, Zhu X. Evaluation on resistance of major rice blast resistance genes to Magnaporthe grisea isolates collected from indica rice in Guangdong Province, China. Chin J Rice Sci. 2008;22(2): 190-6 In Chinese.

31. Xie Q, Guo J, Yang S, Chen Z, Cheng B, Huang Y, et al. Evaluation of blast resistance spectrum and identification of resistance genes in 82 rice germplasm resources. Guangdong Agric Sci. 2015;14:31-5 In Chinese.

32. Chen Z, Tian D, Liang T, Chen Z, Hu C, Wang F, et al. Characterization of the genotypes at the rice blast resistance Pik locus in 229 rice cultivars and important breeding materials. Fujian J Agric Sci. 2016; 31(6):553-9 In Chinese.

33. Li J, Li C, Chen Y, Lei C, Ling Z. Evaluation of twenty-two blast resistance genes in Yunnan using monogenetic rice lines. Acta Phytophylacica Sin. 2005;32(2):113-9 In Chinese.

34. Raffaele S, Farrer R, Cano L, Studholme D, Maclean D, Thines M, et al. Genome evolution following host jumps in the Irish potato famine pathogen lineage. Science. 2010;330(6010):1540-3.

35. Terauchi R, Yoshida K. Towards population genomics of effector-effector target interactions. New Phytol. 2010;187(4):929-39.

36. Stukenbrock E, McDonald B. Population genetics of fungal and oomycete effectors involved in gene-for-gene interactions. Mol Plant-Microbe Interact. 2009;22(4):371-80.

37. Daugherty M, Malik H. Rules of engagement: molecular insights from hostvirus arms races. Annu Rev Genet. 2012;46:677-700. https://doi.org/10.1146/ annurev-genet-110711-155522.

38. Fontaine C, Lovett PN, Sanou H, Maley J, Bouvet J-M. Genetic diversity of the shea tree (Vitellaria paradoxa C.F. Gaertn), detected by RAPD and chloroplast microsatellite markers. Heredity. 2004;93(6):639-48.

39. Hua L, Wu J, Chen C, Wu W, He X, Lin F, et al. The isolation of Pi1, an allele at the Pik locus which confers broad spectrum resistance to rice blast. Theor Appl Genet. 2012;125(5):1047-55.

40. Zhu X, Yang Q, Yang J, Lei C, Wang J, Ling Z. Differentiation ability of monogenic lines to Magnaporthe grisea in indica rice. Acta Phytopathologica Sin. 2004;34(4):361-8 In Chinese.

41. Chuma I, Isobe C, Hotta Y, Ibaragi L, Futamata N, Kusaba M, et al. Multiple translocation of the AVR-Pita effector gene among chromosomes of the rice blast fungus Magnaporthe oryzae and related species. PLoS Pathog. 2011; 7(7):e1002147. https://doi.org/10.1371/journal.ppat.1002147.

42. Dai $Y$, Jia $Y$, Correll J, Wang $X$, Wang $Y$. Diversification evolution of the avirulence gene AVR-Pita1 in field isolates of Magnaporthe oryzae. Fungal Genet Biol. 2010:47(12):973-80.

43. Kang S, Lebrun MH, Farrall L, Valent B. Gain of virulence caused by insertion of a Pot3 transposon in a Magnaporthe grisea avirulence gene. Mol PlantMicrobe Interact. 2001;14(5):671-4. 
44. Zhou E, Jia Y, Singh P, Correll J, Lee FN. Instability of the Magnaporthe oryzae avirulence gene AVR-Pita alters virulence. Fungal Genet Biol. 2007; 44(10):1024-34.

45. Xing J, Jia Y, Peng Z, Shi Y, He Q, Shu F, et al. Characterization of molecular identity and pathogenicity of rice blast fungus in Hunan Province of China. Plant Dis. 2017;101(4):557-61.

46. Li J. Breeding of Yunnan rice. In: Jiang Z, editor. Yunnan Rice. Kunming: Yunnan Science and Technology Press; 1995. p. 185-9. In Chinese.

47. Islam MT, Croll D, Gladieux P, Soanes DM, Persoons A, Bhattacharjee P, et al. Emergence of wheat blast in Bangladesh was caused by a south American lineage of Magnaporthe oryzae. BMC Biol. 2016;14(1):84. https://doi.org/10. 1186/s12915-016-0309-7.

48. Steele K, Humphreys E, Wellings C, Dickinson M. Support for a stepwise mutation model for pathogen evolution in Australasian Puccinia striiformis $\mathrm{f}$. sp. tritici by use of molecular markers. Plant Pathol. 2001;50(2):174-80.

49. Hovmøller M, Justetson A. Rates of evolution of avirulence phenotypes and DNA markers in a northwest European population of Puccinia striiformis $\mathrm{f}$. sp. tritici. Mol Ecol. 2007;16(21):4637-47.

50. Jiménez-Gasco M, Milgroom M, Jiménez-Díaz R. Stepwise evolution of races in Fusarium oxysporum f. sp. ciceris inferred from fingerprinting with repetitive DNA sequences. Phytopathology. 2004;94(3):228-35.

51. Wang C, Guncar G, Forwood J, Teh T, Catanzariti A, Lawrence GJ, et al. Crystal structures of flax rust avirulence proteins AvrL567-a and -D reveal details of the structural basis for flax disease resistance specificity. Plant Cell. 2007;19(9):2898-912

52. Jia Y, Valent B, Lee FN. Determination of host responses to Magnaporthe grisea on detached rice leaves using a spot inoculation method. Plant Dis. 2003:87(2):129-33.

53. Tai T, Tanksley SD. A rapid and inexpensive method for isolation of total DNA from dehydrated plant tissue. Plant Mol Biol Report. 1990;8(4):297-303.

54. Rozas J, Sánchez-Del BJ, Messeguer X, Rozas R. DnaSP, DNA polymorphism analyses by the coalescent and other methods. Bioinformatics. 2003:19(18):2496-7.

55. Clement M, Posada D, Crandall K. TCS: a computer program to estimate gene genealogies. Mol Ecol. 2000;9(10):1657-9.

Ready to submit your research? Choose BMC and benefit from:

- fast, convenient online submission

- thorough peer review by experienced researchers in your field

- rapid publication on acceptance

- support for research data, including large and complex data types

- gold Open Access which fosters wider collaboration and increased citations

- maximum visibility for your research: over $100 \mathrm{M}$ website views per year

At $\mathrm{BMC}$, research is always in progress.

Learn more biomedcentral.com/submissions 